\title{
Pemanfaatan Aplikasi Canva Untuk Meningkatkan Fungsionalitas Media Sosial Pada Pengurus dan Anggota Karang Taruna Kel. Kebon Bawang Jakarta Utara
}

\author{
Yuli Komalasari ${ }^{1}$, Muhammad Muharrom ${ }^{2}$, Achmad Sumbaryadi ${ }^{3}$ \\ 1,2,3 Prodi Teknologi Informasi, Universitas Bina Sarana Informatika \\ Jl. Kramat Raya No 98, Senen, Jakarta Pusat, Indonesia \\ e-mail: ${ }^{1}$ yuli.yks@bsi.ac.id, ${ }^{2}$ muhammad.muu@bsi.ac.id, ${ }^{3}$ achmad.acs@bsi.ac.id
}

\begin{abstract}
Abstrak
Pada kegiatan ini dikenalkan pembelajaran penggunaan aplikasi Canva kepada generasi muda, khususnya Karang Taruna Kelurahan Kebon Bawang Jakarta Utara. Canva adalah salah satu software untuk membuat grafis media sosial, presentasi, poster, dokumen dan konten visual lainnya. Aplikasi ini juga menyediakan beragam contoh desain untuk digunakan. Canva bisa didapatkan secara gratis dan berbayar. Canva bisa diakses melalui perangkat desktop maupun mobile. Beberapa macam desain yang bisa diciptakan dengannya, seperti : Logo, Poster, Banner Iklan, Invoice, Desain Kemasan Produk, Thumbnail Youtube, Infografik, Newsletter, Featured Image Blog dan Konten Media Sosial. Cara mengakses Canva melalui website dengan membuka laman https:www.canva.com. Dalam pelaksanaan pengabdian Masyrakat ini dilakukan secara online menggunakan aplikasi zoom, dijelaskan pada pelaksanaan Pengabdian, Masyarakat agar peserta tersebut dapat mengerti dan memahami gambaran penggunaan Canva dan diharapkan bisa mengaplikasannya dengan baik.
\end{abstract}

Kata Kunci : Canva Platform, Desain grafis, Penggunaan Canva

\begin{abstract}
In this activity, learning how to use the Canva application was introduced to the younger generation, especially Karang Taruna, Kebon Bawang Kota Jakarta Utara. Canva is a graphic design software for creating social media graphics, presentations, posters, documents and other visual content. The app also provides a variety of design examples to use. Canva is available for free and for a fee. Canva is accessible on both desktop and mobile devices. Several kinds of designs can be created with it, such as: Logos, Posters, Advertising Banners, Invoices, Product Packaging Designs, Youtube Thumbnails, Infographics, Newsletters, Featured Image Blogs and Social Media Content. How to access Canva through the website by going to https:www.canva.com. In the implementation of this Community service, it is carried out online using the zoom application, explained in the implementation of Community Service so that participants can understand and understand the description of using Canva and are expected to be able to apply it well.
\end{abstract}

Keywords : Canva Platform, Graphics design, Using canva 


\section{Pendahuluan}

\section{Latar Belakang}

Bagi Generasi muda diperlukan berbagai sarana pelatihan dari berbagai kegaitan, agar para generasi muda tersebut dapat mengisi waktu luang yang positif sehingga berguna bagi pembangunan nasional, untuk itu generasi muda perlu mendapatkan perhatian khusus dan kesempatan yang seluas-luasnya untuk dapat tumbuh dan berkembang secara wajar. Dalam membina generasi muda yang kuat dan tangguh serta mampu memiliki kompetensi dan daya saing global, maka pemuda perlu terus belajar baik secara mandiri maupun dalam bersosialisasi seperti Karang Taruna. Dalam Peraturan Menteri Sosial Nomor 23 Tahun 2013 tentang Pemberdayaan Karang Taruna Pasal 8, Karang Taruna memiliki tugas bersamasama dengan Pemerintah, Pemerintah Provinsi, dan Pemerintah Kabupaten/Kota, dan masyarakat untuk menyelenggarakan pembinaan generasi muda dan menyelenggarakan kesejahteraan sosial.

Pada peraturan tersebut dijelaskan tentang Pemberdayaan Karang Taruna Pasal 1 ayat (2) menyebutkan: Anggota Karang Taruna yang selanjutnya disebut warga Karang Taruna adalah setiap anggota masyarakat yang berusia 13 (tiga belas) tahun sampai dengan 45 (empat puluh lima) tahun yang berada di desa atau kelurahan atau nama lain yang sejenis. Peraturan Gubernur DKI Jakarta No. 8 Tahun 2012, tentang Karang Taruna mengatur ketentuan yang lebih khusus lagi mengenai karang taruna seperti antara lain : organisasi, anggota dan pengurus karang taruna; musyawarah karang taruna; pembinaan; program kerja, keuangan; dan sebagainya. Selain itu, dalam prakteknya, pelaksanaan karang taruna di desa juga ditetapkan lebih khusus oleh lurah atau kepala desa setempat. Sebagai generasi muda Karang taruna diharapkan mampu mencegah timbulnya masalah kesejahteraan sosial, menyelenggarakan kesejahteraan sosial meliputi rehabilitasi, perlindungan sosial, jaminan sosial, pemberdayaan sosial dan sebagai anggota masyarakat terutama generasi muda dapat meningkatkan ekonomi usaha produkdif; memelihara kesadaran dan tanggung jawab sosial setiap anggota masyarakat serta berperan secara aktif dalam penyelenggaraan kesejahteraan social, dan dapat memelihara dan memperkuat semangat kebangsaan Bhineka Tunggal Ika dan tegaknya Negara Kesatuan Republik Indonesia.

Karang Taruna Kelurahan Kebon Bawang Jakarta Utara yang beralamat di Jalan Swasembada Timur Nomor 1, ada ditengah masyarakat dalam upaya mewujudkan fungsi dan peran seperti yang telah diuraikan diatas. Berdasarkan Surat Pendirian Nomor 135 Tahun 2020, Karang Taruna Keluharan Kebon Bawang senantiasa berperan aktif dilingkungan masyarakat, khususnya dilingkungan kelurahan kebon bawang dengan berbagai kegiatan yang telah disusun sehingga bermanfaat bagi warga karang taruna maupun masyarakat secara umum.

Diperlukan suatu wadah untuk membina dan mengarahkan generasi muda tersebut. Pembinaan terus dilakukan, baik dari tingkat pusat maupun daerah yang sesuai dengan bidangnya, sehingga bisa berpartisipasi di tengah masyarakat. Wadah tersebut dapat membentuk suatu organisasi yang nantinya akan menjadi wadah pernbinaan generasi muda tersebut baik di perkotaan ataupun pedesaan. Salah satu wadah pembinaan dan pengembangan generasi muda yaitu Karang Taruna.

Tujuan dibentuknya karang taruna sebagai organisasi pemuda yaitu sebagai wadah pembinaan dan pengembangan kreativitas generasi muda untuk menjalin persaudaraan dan kebersamaan menjadi mitra organisasi di lembaga, kepemudaan ataupun pemerintah untuk menghasilkan suatu kreativitas. Karang taruna diharapkan mampu membantu dalam bidang kesejahteraan 
sosial baik di masyarakat dilingkungan sekitar ataupun di wilayah lain dan berperan serta dalam pembangunan. Selain mewujudkan kesejahteraan sosial di kelurahan setempat, karang taruna berfungsi menjadikan potensi kreatifitas muda agar secara terarah dan membina dirinya sebagai pendukung pembangunan wilayahnya.

Karang Taruna secara eksplisit merupakan wadah pembinaan dan pengembangan generasi muda yang aktif dalam pembangunan nasional serta dalam bidang kesejahteraan sosial dimana Karang Taruna sebagai salah satu wadah kreativitas generasi muda yang memiliki peranan sangat penting bagi tumbuh kembangnya kegiatan yang dilakukan (Muslam et al., 2016)

Banyaknya pengguna media sosial saat ini, semakin banyak hal-hal bisnis dan kegiatan lainnya yang bisa dilakukan dimana saja. Kegiatan bisnis tersebut bisa dilakukan dikantor, dirumah ataupun pada saat pelaku bisnis atau usaha berada dimana saja. Dengan media sosial pelaku usaha dapat berinteraksi dimana saja.

Remaja Karang Taruna Kelurahan Kebon Bawang merupakan kelompok remaja yang kreatif, yang gemar mengikuti pelatihan-pelatihan. Untuk menambah ilmu, wawasan serta pengalaman dibidang teknologi, agar lebih kreatif lagi, diberikanlah pelatihan mengenai Pemanfaatan Aplikasi Canva Untuk Meningkatkan Funsionalitas media bagi anggota Karang Taruna. Para peserta Karang Taruna yang telah mengikuti pelatihan sampai selesai, diharapkan dapat mengisi waktu pelatihan dengan sebaik-baiknya dan menggunakan aplikasi Canva dalam meningkatkan fungsionalitas Media.

\section{Perumusan Masalah}

Masalah yang dihadapi remeja Karang Taruna Kebon Bawang adalah :

a. Belum mengenal penggunaan aplikasi Canva

b. Beberapa anggota pernah mendengar aplikasi Canva, tetapi belum sepenuhnya memahami tentang aplikasi Canva

\section{Tujuan Kegiatann}

a. Memberikan pelatihan penggunaan aplikasi Canva bagi anggota Karang Taruna di Kelurahan Kebon Bawang.

b. Memberikan pengetahuan dan keterampilan di bidang design grafis bagi anggota Karang Taruna di Kelurahan Kebon Bawang.

c. Melatih para peserta dalam bidang komputer, khususnya dalam menambah aktifitas yang positif sebagai remaja.

\section{Manfaat Kegiatan}

a. Membantu kegiatan remaja agar lebih kreatif khususnya dimasa pandemic saat ini.

b. Dengan banyaknya kegiatan yang diberikan, diharapkan para remaja lebih kreatif lagi dalam segala hal, khususnya dibidang komputer.

\section{Metode}

Metode pelaksanaan kegiatan Pengabdian Masyarakan ini adalah diadakan pelatihan kepada para Remaja Karang Taruna di Kelurahan Kebon Bawang Jakarta Utara mengenai aplikasi Canva, cara menggunakannya dan kegunaan dari aplikasi Canva tersebut. Metode kegiatan pelatihan ini dilakukan berdasarkan pendekatan proses pembelajaran teori dan pembelajaran praktek (Gata et al., 2020). 


\section{ABDITEKNIKA}

Jurnal Pengabdian Kepada Masyarakat

Sebelum kegiatan dimulai, dilakukan survey ke lokasi Pengabdian Masyarakat, Persiapan materi yang akan disampaikan, Pelaksanaan kegiatan, melakukan monitoring dan evaluasi kegiatan setelah pelaksanaan Pengabdian Masyarakat dilakukan.

Secara rinci Proses pelaksanaan Pengabdian Masyarakatan yang dilaksanakan secara online melalui media zoom meliputi :

1. Memberikan Infromasi kepada anggota Karang Taruna tentang aplikasi Canva dan cara penggunaannya.

2. Untuk mendapatkan software CANVA, dapat membuat akun CANVA dan Mendownloadnya, bisa menggunakan perangkatan Komputer atau mobile phone.

3. Mengenalkan CANVA serta memberikan informasi cara-cara penggunaan CANVA

4. Diharapkan aplikasi CANVA untuk membantu kegiatan Karang Taruna, dll.

\section{Hasil dan Pembahasan}

1. Pelatihan dilakukan menggunakan media zoom

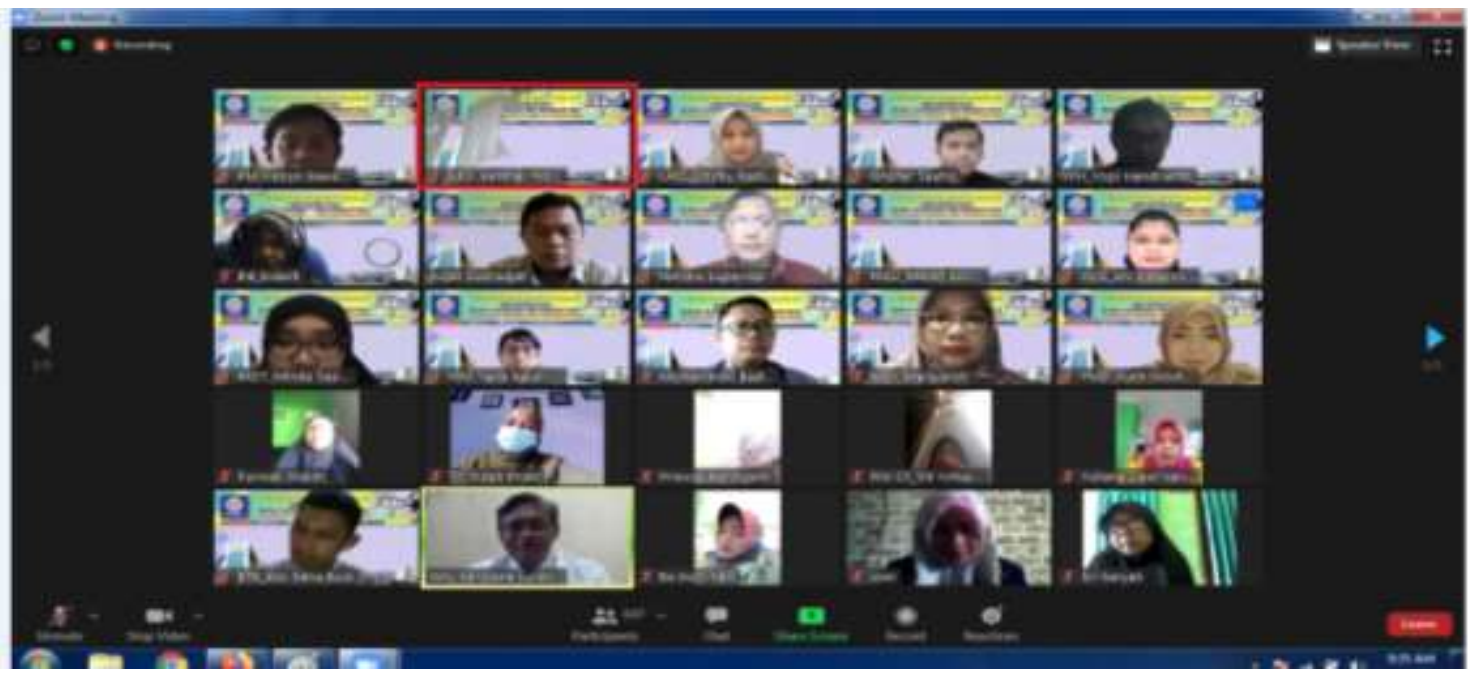

Gambar 1. Pembukaan Pengabdian Masyarakat

2. Pelatihan dimulai

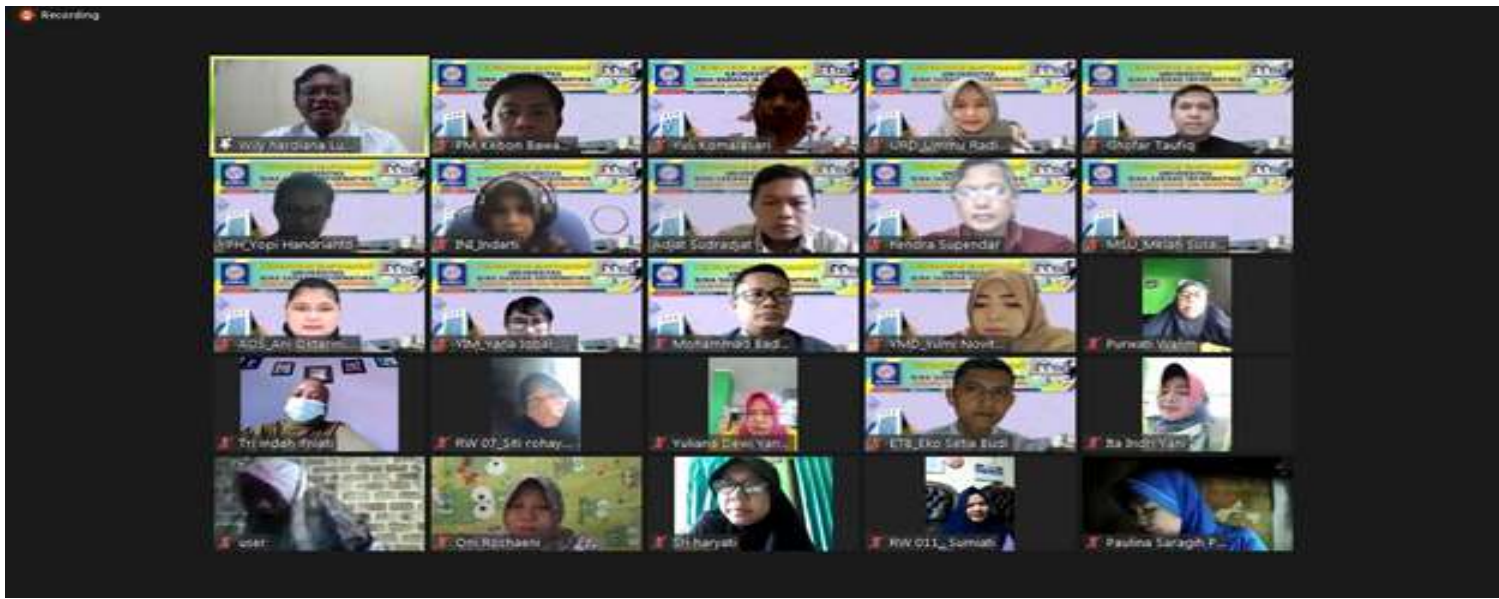

Gambar 2. Pelatiahan dimulai 


\section{ABDITEKNIKA}

Jurnal Pengabdian Kepada Masyarakat

Volume 1 Nomor 2 Oktober 2021

ISSN 2775-1694

3. Dimulai dengan pengenalan Aplikasi Canva, cara mendownload dan penggunaan aplikasi tersebut

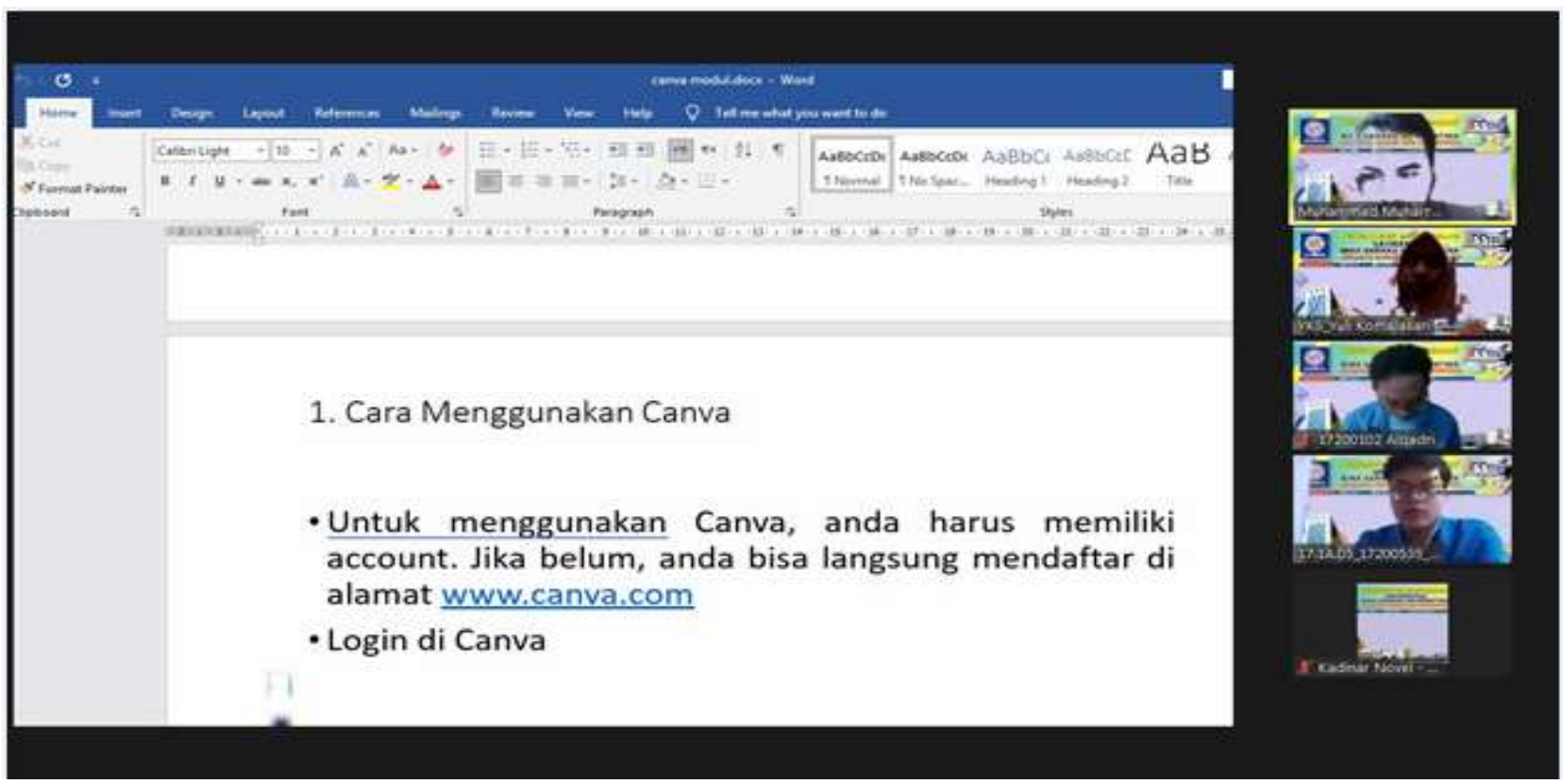

Gambar 3. Pengenalan aplikasi Canva

4. Diperkenalkan juga cara penggunaan Canva menggunakan Mobile Phone

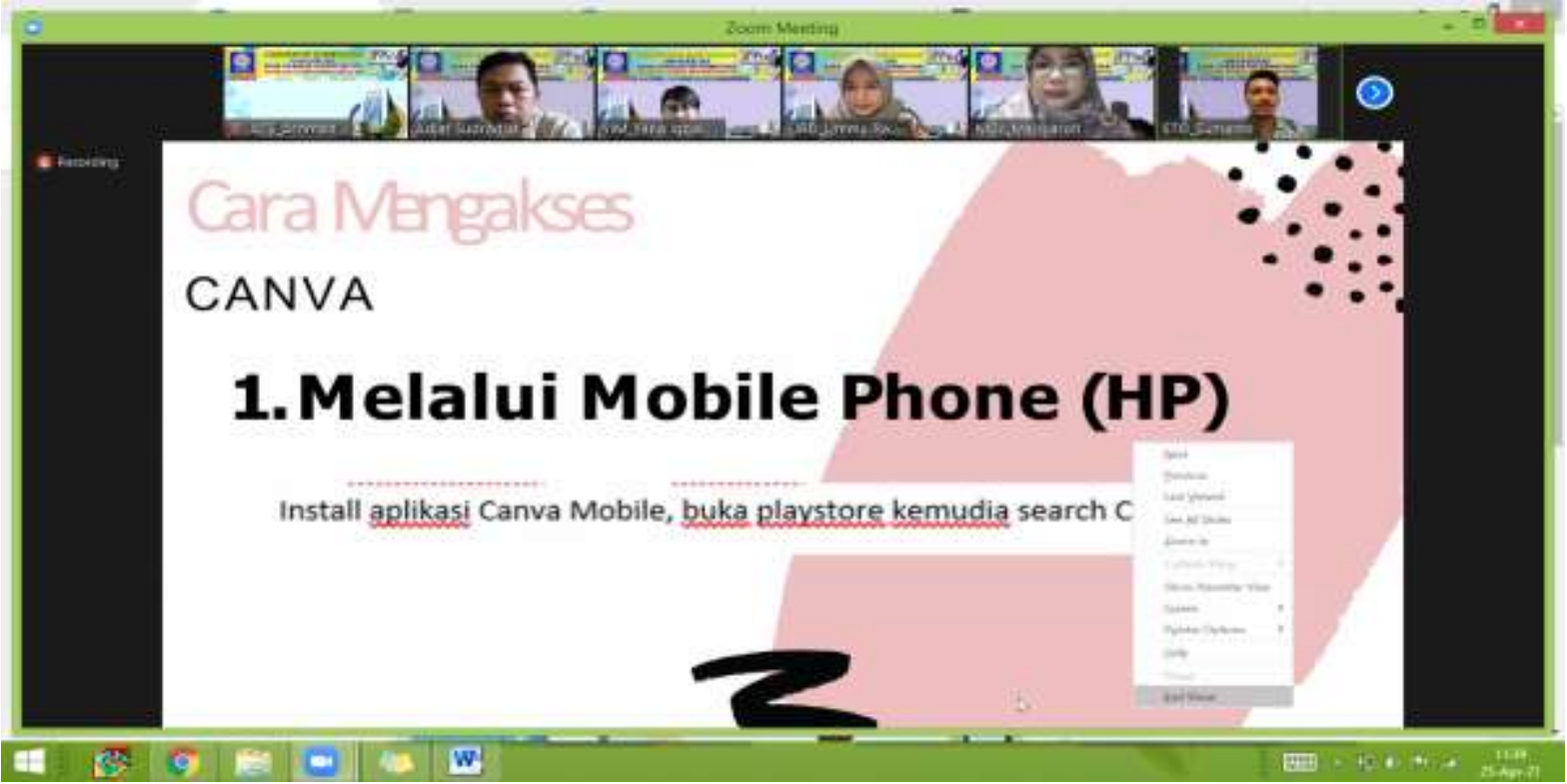

Gambar 4. Pengenalan aplikasi Canva melalui Mobile Phone 
Pelaksanaan pelatihan Penggunaan aplikasi Canva mendapat tanggapan yang positif dari peserta, pengurus dan Bapak Lurah Kebon Bawang. Alhamdulillah para peserta antusias dengan materi yang diberikan, dibuktikan dengan adanya kuis yang dilakukan di akhir acara, semua peserta antusias menjawab semua pertanyaan, sebagai respon dari materi yang telah diberikan.

\section{Kesimpulan}

Dari kegiatan Pengabdian Masyarakat Pemanfaatan Aplikasi Canva Untuk Meningkatkan Fungsionalitas Media Sosial Pada Pengurus dan Anggota Karang Taruna Kelurahan Kebon Bawang Jakarta Utara dapat mengetahui lebih banyak lagi tentang penggunaan aplikasi tersebut. Kegiatan ini membawa dampak yang positif, khususnya dimasa pandemi ini, diharapkan mereka bisa lebih banyak melakukan kreatifitas menggunakan aplikasi Canva

\section{Daftar Pustaka}

Arif, M. R., Adi, A. S., \& Remaja, P. P. (2014). Abstrak. 1.

Gata, G., Imelda, I., Yuliazmi, Y., \& Siswanto, S. (2020). Pelatihan Pengelolaan Blog Untuk Remaja Di RPTRA Manunggal Kelurahan Petukangan Selatan. Jurnal Abdimas BSI: Jurnal Pengabdian Kepada Masyarakat, 3(1), 39-44. https://doi.org/10.31294/jabdimas.v3i1.6706

Haryani, H., Oktiani, N., Kuspriyono, T., \& Akil, I. (2021). Sistem Pengelolaan E-Commerce (SisPEC) Produk Adpers Art Community Kelurahan Sukatani Kecamatan Tapos Depok. Jurnal Abdimas BSI: Jurnal Pengabdian Kepada Masyarakat, 4(1), 31-37. https://doi.org/10.31294/jabdimas.v4i1.7929

Mulyani, Y. S., Wibisono, T., Alawiyah, T., \& Warnilah, A. I. (2019). Pelatihan Komputer Dasar Untuk Mendukung Proses Kegiatan Belajar Mengajar (Kbm) Bagi Guru-Guru Ra/Tpq/Dta Al-Ishlaah Kota Tasikmalaya. Jurnal Abdimas BSI: Jurnal Pengabdian Kepada Masyarakat, 2(2), 234-240. https://doi.org/10.31294/jabdimas.v2i2.5768

Muslam, M., Fatkuroji, F., \& Muntoli'ah, M. (2016). Pemberdayaan Pemuda Karang Taruna Melalui Program Remaja Pintar Berbasis Agama Desa Wisata Kandri Kota Semarang. Dimas: Jurnal Pemikiran Agama Untuk Pemberdayaan, 16(1), 145. https://doi.org/10.21580/dms.2016.161.896

Provinsi, G., Khusus, D., \& Jakarta, I. (2012). Ta lIn 2005. 1-12.

Rahmatullah, R., Inanna, I., \& Ampa, A. T. (2020). Media Pembelajaran Audio Visual Berbasis Aplikasi Canva. Jurnal Pendidikan Ekonomi Undiksha, 12(2), 317-327.

Sholeh, M., Rachmawati, R. Y., \& Susanti, E. (2020). Penggunaan Aplikasi Canva Untuk Membuat Konten Gambar Pada Media Sosial Sebagai Upaya Mempromosikan Hasil Produk Ukm. SELAPARANG Jurnal Pengabdian Masyarakat Berkemajuan, 4(1), 430. https://doi.org/10.31764/jpmb.v4i1.2983 


\section{ABDITEKNIKA}

Jurnal Pengabdian Kepada Masyarakat

Volume 1 Nomor 2 Oktober 2021

ISSN 2775-1694

Wulandari, O. A. D., Barokah, S., Azhar, N. Al, \& Ghazali, H. Al. (2021). Penerapan Fintech Dengan Aplikasi Ovo Sebagai Digital Payment Bagi Ibu - Ibu PKK Rt 02/Rw 04 Di Dukuhwaluh Purwokerto. Jurnal Abdimas BSI: Jurnal Pengabdian Kepada Masyarakat, 4(1), 1-6. https://doi.org/10.31294/jabdimas.v4i1.6979 